\title{
A New Diterpenoid Isolated from Isodon japonica Structure Elucidation by NMR Spectroscopy
}

\author{
Bao-Lin Li ${ }^{k, *}$ and Yuan-Jiang Pan ${ }^{4 * *}$ \\ ${ }^{\dagger}$ Department of Chemisiry, Zhejiang Liniversity, Hangshou 310027, China \\ ${ }^{*}$ School of Chemistry and Material Science. Shataxi Normal Unwersity; Kiam 710062. China \\ Received November 28.2001
}

Keywords : Isodon japonica. Taibaijaponicain E. Diterpenoid.

From the plants of the genus Isodon (I abiatae), many deterpenoids having ent-kaurene, 7,20-epoxy-ent-kaurene, 6,7-seco-ent-kaurene, 8,9-seco-ent-kaurene, 6-epi-ent-gibberelene, ent-isopimanthrene and abietene skeletons have been isolated and characterized.' These substances have shown various biological activities such as antibacterial, anitumor and cytotoxic effects ${ }^{2-3}$ etc. In a previous study of the chemical constituents of $/ \mathrm{sodon}$, we reported on the isolation of two new ent-kaurene diterpenoids, taibairubescensins A and B. ${ }^{1}$ During the course of our systematic search for biologically active substances from plants of the genus $I s o d o m$, recently, we examined diterpenoid constituents of Isodon Japonica (Burm, f.) Hara (labiatae) collected from Taibai Mountain. China, and isolated a new diterpenoid. natmed taibaijaponicain $\mathrm{E}$ : (1), along with four known compounds, norhendosin A (2), nodosin (3), rabdophyllin G (4), lasiodin (5). We report here the isolation and structure elucidation of new compound by a combination of NMR techniques, including DГPT, HMBC and NOFSY.

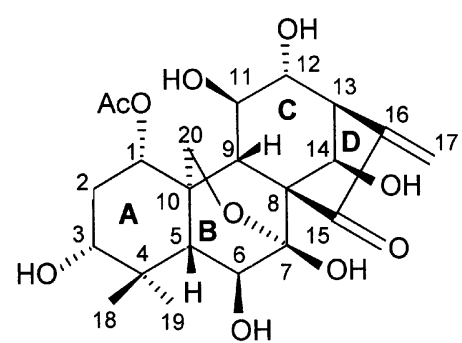

Jaibaijaponicain $E$ (1) has a molecular formula as $\mathrm{C}_{22} \mathrm{H}_{30} \mathrm{O}_{10}$ that was determined by $\mathrm{FABMS}$ and elemental analysis. The ${ }^{1} \mathrm{H},{ }^{13} \mathrm{C}$ and $\mathrm{DEI} \mathrm{P}^{\mathrm{C}}$ NMR spectra of $\mathbf{1}$ (see Table 1) showed the signals for three methyl groups (including a methyl of acetyl group), two methylene groups, nine methine groups, four quaternary carbons, two olefinic carbons, one ketonic carbon and one ester carbonyl carbon. Its UV and IR spectra showed characteristic absorption bands for a five-membered ring ketone conjugated with an exo-Inethylene (233.2 $\left.\mathrm{nm}: 1737.1644 \mathrm{~cm}^{-1}\right)$. The IR spectrum also revealed hydroxyl and acetyl bands at 3438, 3337 and $1712 \mathrm{~cm}^{-1}$. One of four quaternary carbons had a chemical

"To whom correspondence should be addressed. Phone: -86-57187951264: t-mail: panyuanjiang(a) zjuem.zju.edu.cn shift signal at $\delta 98.3 \mathrm{ppm}$, and the 'H NMR spectrum exhibited an $A B$ peak signals at $\delta 4,26,4.10 \mathrm{ppm}$. Considering the structures of diterpenoids from the genus 1 sodon, these data suggested that $\mathbf{I}$ was a 7,20 -epoxy-ent-kaurane type diterpenoid with one acetoxyl group and six hydroxyl groups.

In HMBC spectrum of $\mathbf{I}$ (see Table 1), the carbon signal at $\delta 40.5(\mathrm{~s})$ and the proton signal at $\delta 3.02(1 \mathrm{H}$, br $\mathrm{d}, J=9.7$ $\mathrm{Hz}$ ) were assigned to the resonances of $\mathrm{C}-10$ and $\mathrm{H}-13 \alpha$, respectively. The carbon signal at $\delta 40.5$ correlated with the proton signal at $\delta 4.63 \mathrm{ppm}(1 \mathrm{H}, \mathrm{dd}, J=11,3,5.6 \mathrm{H} 7)$ which showed cross-peaks with the carbon signals at $\delta 170.1$ (s, $\mathrm{CH}_{3} \mathrm{COO}-\mathrm{)}$ and $25.8(\mathrm{t}, \mathrm{C}-2)$. These indicated that the acetoxyl group was located at the $\mathrm{C}-1$ position. The coupling constants between $\mathrm{H}-\mathrm{l}$ and $2 \mathrm{H}-2$ were 11.3 and $5.6 \mathrm{~Hz}$. which suggested that the dihedral angles between $\mathrm{H}-1$ and $\mathrm{H}-2$ approximated $180^{\circ}$ and $60^{\circ}$, and the relative configuration of the acetoxyl group at $\mathrm{C}-1$ was in a $\alpha$-orientation. Meanwhile, HMBC correlations from the carbon signal at $\delta$ $76.0(\mathrm{~d}, \mathrm{C}-1)$ to the proton signals at $\delta 1.44(1 \mathrm{H}, \mathrm{m}, \mathrm{H}-2 \alpha)$ and $1.38(1 \mathrm{H}, \mathrm{m}, \mathrm{H}-2 \beta)$, and its DГРT spectrum indicated that $\mathrm{C}-2$ was a methylene group. Since there was not hydroxyl group at C-13 deduced from the chemical shifts of $\mathrm{C}-13$ (44.1d) and $\mathrm{H}-13$, and one out of two methylene groups was accounted for $\mathrm{C}-20$, six hydroxyl groups should be unambiguous located at C-3, C-6, C-7, C-11, C-12, C-14, respectively. Previous studies of the NMR spectra of 7,20 epoxy-ent-kaurene type diterpenoids showed that ring $\mathrm{A}$ adopts the chair conformation, ring $\mathrm{B}$ has a boat conformation. ring $\mathrm{D}$ is in an envelope conformation, and ring $\mathrm{C}$ is in either a chair or a boat conformation depending on the substituents in ring $\mathrm{C}$; and that $\mathrm{HO}-6$ and $\mathrm{HO}-7$ are in the $\beta$ orientations. ${ }^{5}$ In compound 1 , the ring $\mathrm{C}$ should be in a boat conformation and the $\mathrm{HO}-14$ should be in a $\beta$-orientation by considering the coupling constants of $\mathrm{H}-\mathrm{I} 4 \alpha$ and $\mathrm{H}-\mathrm{I} 3 \alpha$. The relative configurations of the hydroxyl groups at $\mathrm{C}-3, \mathrm{C}$ 11 and $\mathrm{C}-12$ were established by a NOESY experiment. most of the NOESY correlations are shown in Figure $\mathrm{l}$. The following cross-peaks were observed: from the proton signal at $\delta 3.67(\mathrm{H}-3)$ to the signals at $\delta 1.35(\mathrm{H}-5 \beta)$ and $4.63(\mathrm{H}-$ $1 \beta) ; 5.41(\mathrm{H}-1 \mathrm{l})$ to the signals at $\delta 4.92(\mathrm{H}-14 \alpha)$ and 3.02 $(\mathrm{H}-13 \alpha) ; 4.93(\mathrm{H}-12)$ to the signal at $\delta 2.00(\mathrm{H}-9 \beta)$. On the basis of above evidences, the three hydroxyl groups at $\mathrm{C}-3$. $\mathrm{C}-11$ and $\mathrm{C}-12$ were assigned to be in the $\alpha, \beta, \alpha$-orientations. respectively. Therefore, taibaijaponicain $E(\mathbf{l})$ was elucidat- 


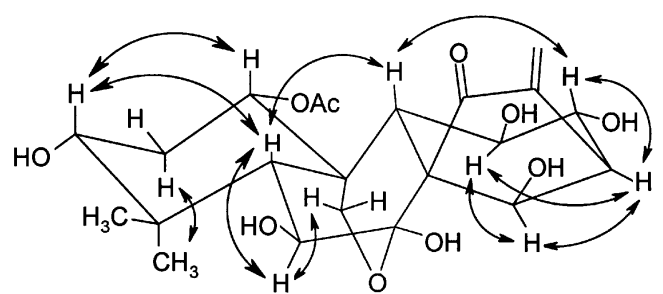

Figure I. Major NOE corrclations in $\mathbf{I}$.

ed to be $1 \alpha$-aectoxy- $3 \alpha, 6 \beta, 7 \beta, 11 \beta, 12 \alpha, 14 \beta$-hexahydroxy7,20-epoxy-ent-kaur-16-en-15-one.

Compounds 2, 3, 4 and 5 were identified as diterpeneoids, norhendosin A, nodosin, rabdophyllin $G$ and lasiodin by comparison of the physical and ${ }^{13} \mathrm{C}-\mathrm{NMR}$ data with reported ones [6]-[10].

\section{Experimental Section}

General Methods. FAB mass spectrum was recorded on a 7.AB-HS Instrument (data system: MASPEC II). Flementary analysis was performed on a $\mathrm{P}[2400 \mathrm{CHN}$ elemental ana-

Table 1. ${ }^{13} \mathrm{C},{ }^{1} \mathrm{H}$ NMR data and principal H.MBC correlations of 1 in acetone-d

\begin{tabular}{|c|c|c|c|}
\hline Proton & $\delta c^{c s}$ & $\delta_{\mathrm{H}} \cdot$ mult. intgr. $(/ . \mathrm{Hz})$ & HMBC (carbon) \\
\hline $1 \beta$ & $76.0 \mathrm{~d}$ & $\begin{array}{l}4.63 . \mathrm{dd} .1 \mathrm{HL} . \\
(11.3 .5 .6)\end{array}$ & $\begin{array}{l}(2) .9 .(10) .20 . \text { Aco } \\
(170.1 \mathrm{ppm})\end{array}$ \\
\hline $2 \alpha$ & $25.8 \mathrm{t}$ & 1.44. m. $\mathrm{H}$ & (1). (3) \\
\hline $2 \beta$ & & $1.38 . \mathrm{m} . \mathrm{lH}$ & (1). (3) \\
\hline $3 \beta$ & $74.6 \mathrm{~d}$ & 3.67. m. $1 \mathrm{H}$ & (4) \\
\hline 4 & $34.1 \mathrm{~s}$ & - & - \\
\hline $5 \beta$ & $61.0 \mathrm{~d}$ & 1.35. overlap. $1 \mathrm{H}$ & (4). (6). (10). 19 \\
\hline $6 \alpha$ & $74.4 \mathrm{~d}$ & 3.67. overlap. 1H & $(5) .(7) .10$ \\
\hline 7 & $98.3 \mathrm{~s}$ & - & - \\
\hline 8 & $62.8 \mathrm{~s}$ & - & - \\
\hline $9 \beta$ & $53.5 \mathrm{~d}$ & 2.00 br s. $1 \mathrm{H}$ & $(8) .(10) .20$ \\
\hline 10 & $40.5 \mathrm{~s}$ & & \\
\hline $11 \alpha$ & $73.7 \mathrm{~d}$ & 5.41. br d. 1H. (9.2) & $8 .(12) .13$ \\
\hline $12 \beta$ & $74.5 \mathrm{~d}$ & $4,93, \mathrm{~m}, 1 \mathrm{H}$ & 9 \\
\hline $13 \alpha$ & $44.1 d$ & 3.02, brd. $11 \mathrm{I}_{.}(9.7)$ & $11 .(12) .(14) .15 .(16) .17$ \\
\hline $14 \alpha$ & $73.9 \mathrm{~d}$ & 4.92, overlap. $11 \mathrm{I}$ & (8). $12,15,16,17$ \\
\hline 15 & $209.1 s$ & - & - \\
\hline 16 & $153.1 \mathrm{~s}$ & - & - \\
\hline $17 a$ & $119.4 t$ & $6.02,5.111$ & $13.15 .(16)$ \\
\hline $17 b$ & & 5.52 .8 .111 & $13.15 .(16)$ \\
\hline 18 & $22.0 \mathrm{~g}$ & 1.07.s. $31 \mathrm{H}$ & (4). 19 \\
\hline 19 & 32.90 & $1.11 .5 .3 H$ & (4). 18 \\
\hline $20 \mathrm{a}$ & 63.60 & $\begin{array}{l}\text { 4.26. 4.10. Ab3. dd. } \\
\text { each 111. (10.7.1.3) }\end{array}$ & $5.9 .(10)$ \\
\hline $20 \mathrm{~b}$ & & & $5.9 .(10)$ \\
\hline OAC & $\begin{array}{l}21.3(q) \\
170.1(\mathrm{~s})\end{array}$ & 1.94. s. $3 \mathrm{H}$ & $\operatorname{AcO}(170.1 \mathrm{ppm})$ \\
\hline $\mathrm{HO}-6$ & & 6.15. d. $1 \mathrm{H} .(10.5)$ & (6). 7 \\
\hline $\mathrm{HO}-7$ & & 6.38. s. $1 \mathrm{H}$ & 6. (7). 8 \\
\hline
\end{tabular}

"The ${ }^{1 "} \mathrm{C}$ NMR multiplicities were obtained by the DГPT spectrum. "Two-bond correlations are indicated in parentheses. lyzer. UV spectrum was recorded in $\mathrm{MeOH}$ on a HITACH] U-2000 spectrophotometer. IR spectrum was recorded in $\mathrm{KBr}$ pellets on a Nicolet AVATAR 360 FT-IR spectrometer. The optical rotation was measured with a JASCO-20C polarimeter. NMR spectra were recorded on a Bruker AM400 Instrument. The chemical shift values are given in ppm using TMS as the internal standard.

Plant Material. The plant material was collected in Taibai Mountain, Shaanxi Province, P. R. China, in August 1997. It was identified as Isodon japonica (Burm. f.) Hara. A voucher specimen (SNU 97-08-03, 1.i) was deposited in the Herbarium of l.ife Science College, Shaanxi Normal University.

Extraction and lsolation. The dried powdered leaves and tender branches of Isodon japonica $(7.0 \mathrm{~kg})$ were extracted with $95 \%$ ГtOH $(18 \mathrm{I}, \times 2)$ at room temperature for 7 days. After removal of the solvent in vacuo, the residue was partitioned in $\mathrm{H}_{2} \mathrm{O}$ and extracted with petroleum ether (4 I. × 3 ) and FtOAc $(4 \mathrm{I}, \times 3)$, respectively. The FtoAc extract $(130 \mathrm{~g})$ was subjected to colume chromatograph (CC) on silica gel (3 kg, 200-300 mesh), eluting with $\mathrm{CHCl}_{3}$ and increasing proportions of $\mathrm{Me}_{2} \mathrm{CO}\left(\mathrm{CHCl}_{3} / \mathrm{Me}_{2} \mathrm{CO}\right.$ : from $10: 0$ to $0: 10)$. The eluate from $8: 2\left(\mathrm{CHCl}_{3} / \mathrm{Me}_{2} \mathrm{CO}\right)$ was further submitted to repeated $\mathrm{CC}$ to give 1 (224 $\mathrm{mg}$, $0.0032 \%), 2$ (273 mg. $0.0039 \%), 3$ (110 mg. $0.0016 \%), 4$ (67 mg, $0.00096 \%), 5(3.3 \mathrm{~g}, 0.047 \%)$.

Taibaijaponicain F (1): An amorphous white powder. FABMS $\left.m / z: 461[\mathrm{M}-\mathrm{L} . \mathrm{i}]^{-}, 477 \mathrm{[M}^{\mathrm{N}} \mathrm{Na}\right]^{-}$, and elemental analysis: $\mathrm{C} 58.0 \%, \mathrm{H} 6.7 \%$ (calcd. C $58.1 \%, \mathrm{H} 6.6 \%$ ) for $\mathrm{C}_{22} \mathrm{H}_{36} \mathrm{O}_{1[k}[\alpha]_{1}{ }^{22}:-42.3^{\circ}(\mathrm{c}=0.50$, acetone $) ; \mathrm{UV} \lambda_{\max }(\mathrm{MeOH}) ;$ $233.2 \mathrm{~nm}(\log \varepsilon=3.38), \mathrm{IR} \quad v_{\max }^{\mathrm{KBr}} \mathrm{cm}^{-1}: 3438,3337,2963$, $1737,1712,1644,1245$ and $1071 .{ }^{1} \mathrm{H},{ }^{13} \mathrm{C}$, DГРТ NMR spectral data and principal HMBC correlations are listed in Table 1. Most of NOFSY correlations are shown in Figure 1.

Acknowledgment. We are grateful for tinancial support from the Natural Science Foundation of Shaanxi Province, P. R. China. We would like to thank Prof. Xianhua Tian, life Science College, Shaanxi Normal University (P. R. China), for identification of the plant samples.

\section{References}

1. Guo. Y. W.: Chen. P. Y. Zhong Cao ko 1991. 22. 371-375.

2. Fujita, T: Takeda Y.: Sun, II. D.: Minami, Y: Marunaka, T.: Takedal S.: Yamada Y.: Togo. T. Plemta Medtea 1988. 5t. 414-417.

3. Nagao. Y.: Ito. N.: Kohnor. I:: Kuroda. Il.: Fujita. I: (hem. Pham. Bull. 1982. 30.727-729.

4. Li. B. L.: Chen. S. N.: Shi. Z. X.: Chen. Y. Z. Phyochemistm 2000. $53.855-859$.

5. Xu. (i. Y. Acta (himica Sinica 1985 +3, 35-43.

6. Meng. X. I.: Chen. Y. Z.: Cui. Y. X.: Cheng. I. I. J. Nat Prod. 1988. 51. $812-816$.

7. Osawa. K.: Yasuda. H.: Maruyana. I.: Morita. H.: lakeya. K.: Itokawa H.: Okuda. K. Chem. Pham. Bull. 1994. $42.922-925$.

8. Chen. Y, Z.: Wu. Z. W.: Cheng. P. Y. Acta Chimica Simica 1984. $42,645-649$.

9. Cheng. P. Y.: Xu. M. J.: L.in. Y. L.: Shi. I. C. Acta Phamatertica Sincia 1982.17.917-921.

10. Li. G. Y.: Song. W. L.: Ji. Q. Y.: Wang. Y. L. Lhong keo long Bero 1984. 9.221-222. 